\title{
COVID-19: Knowledge, Perception and Infection Control Practice of Health Care Workers (A Suggested Ward-based Educational Package)
}

\author{
Ghada Thabet Mohammed ${ }^{1}$, Anaam Mohammed Hassan ${ }^{2}$, Nahed Shawkat Abo Elmagd ${ }^{3}$, Nagwa Mohamed \\ Gamal $^{4}$, Zuhair Mohammed Mohammed Saleh ${ }^{5} \&$ Shaymaa Sayed Khalil ${ }^{6 .}$ \\ 1. Fellow Medical-Surgical Nursing, Assiut University Hospitals, Assiut University, Egypt. \\ 2. Fellow Medical-Surgical Nursing, Assiut University Hospitals, Assiut University, Egypt. \\ 3. Assistant Professor Nursing Administration, Faculty of Nursing Assiut University, Egypt. \\ 4. Fellow Community Health Nursing, Assiut University Hospitals, Assiut University, Egypt. \\ 5. Assistant Professor of Pathology, Department of Medical Laboratory technology, Faculty of Applied Medical \\ Sciences, University of Tabuk, Kingdom of Saudi Arabia, Egypt. \\ 6. Lecture of Medical Surgical Nursing, Faculty of Nursing Assiut University, Egypt.
}

\begin{abstract}
Background: Increasing infection control knowledge and skills of the health care providers forward will enhance their perception toward COVID-19. Aim: Assess knowledge, perception and infection control practice of health care workers regarding Covid-19 and design a suggested ward-based educational package. Research Design: Multicentric, cross sectional descriptive study. Setting: Assiut University Hospitals in Upper Egypt. Sample: 500 HCWs including nurses, assistant nurse, and workers from all healthcare facilities at Assiut University Hospitals. Tools : $\{\mathbf{I}\}$ A 23-item survey instrument (WHO, 2020), divided into three parts; Demographic characteristics, knowledge and perception assessment. $\{\mathbf{I I}\}$ Observation checklist for health care workers' infection control practice, it consisted of 3 main items: hand hygiene steps, donning and doffing PPE, and coughing etiquette. In addition, \{III\} A suggested ward-based educational package for health care workers. Results: The majority of HCWs had poor level of knowledge and perception, and had an unsatisfactory level of infection control practice regarding COIVD-19. There was statistically significant difference between HCWs' knowledge and practice, also between perception and practice except among nurses. Conclusion: The present study concluded that the majority of HCWs had low level of both knowledge, perception and infection control practice. So, it was necessary to assess these and improve it. Recommendations: Urgently implement strategies as educational interventions to protect healthcare workers in the time of the COVID-19 pandemic.
\end{abstract}

\section{Keywords: COID-19, Educational Package Health Care Workers, Infection Control, Knowledge, Perception, Practice \& Ward-based.}

\section{Introduction}

Since announcement of the Chinese authorities in Wuhan city on novel corona virus disease (COVID19) in December 2019, the epidemic has expanded from Wuhan throughout China and disseminated to every country across the world. As of 10 June, there were 7.5 million confirmed COVID-19 cases and 410 thousand deaths worldwide (Zhang et al., 2020). COVID -19 infection occurs mainly by contact or droplet transmission. In addition, airborne infection may develop in case of respiratory aerosols production with patient respiratory activity or medical procedures. At this time, there are no specific vaccines or treatments for COVID-19. However, there are many ongoing clinical trials evaluating potential treatments (Huang et al., (2020).

The ward education is widely regarded as the most suitable method for teaching and has consistently been identified as the preferred place for learning by nurses. Much of the literature refers specifically to those undertaking pre-registration programs and postbasic courses. However, with the arrival of word based education selecting the most appropriate venue for learning about the clinical aspects of care has become relevant to all qualified nurses. Although it is to be welcomed, for many nurses employed in clinical grades it will not be without draw-backs (Alshahrani, 2020).

In Egypt, the first case of COVID-19 was confirmed on 14 February 2020, then the number of confirmed cases and death increased (WHO, 2020). Concurrently, there is a parallel rise in the number of infected health care providers including physicians and nurses. This study aimed to identify working conditions among Egyptian health care providers during COVID-19 epidemic as well as the perception of stigma and worry from contracting this infection and their predictors (Elmeiligy et al., 2020). 
Significance of the study:

Amidst to current pandemic, World Health Organization(WHO) has issued several guidelines, started online courses and training sessions to raise awareness and preparedness regarding prevention and control of COVID-19 among HCWs (Bhagavathula et al., 2020).

In Egypt, the Egyptian Ministry of Health cooperated in launching a campaign an electronic initiative through the most used sites to increase awareness among Egyptians of the symptoms and methods of preventing the emerging pandemic.

Assiut University Hospitals that medical edifice in Upper Egypt, which contains 10 hospitals and includes 2030 human resources from various categories of nursing and 3127 of support services, (Assiut University Hospital records, 2020) that provide medical service to all governorates of Upper Egypt.

Conducting educational intervention in the workplace increase the participation of staff who would otherwise have been too busy to attend. Surveillance of infection control regarding Covid-19 infection was not undertaken routinely at Assiut University hospitals so the success of the intervention was determined by the incidence of the pandemic infection.

Aims of the study to

1. Assess knowledge, perception and infection control practice of health care workers regarding Covid-19.

2. Develop the suggested ward-based educational package.

\section{Research question}

What is the level of health care workers' knowledge, perception and infection control practice regarding COVID-19?

\section{Subject and Methods}

Research design: Multi-centric, cross sectional descriptive study was utilized in this study.

Setting and subject: The study was conducted at Assiut University Hospitals in Upper Egypt on $500 \mathrm{HCWs}$ including nurses, assistant nurse, and workers from all healthcare facilities at Assiut University Hospitals.

The study was conducted during the period from $1^{\text {st }}$ January to $30^{\text {th }}$ April 2020, Sample size calculated by following equation according to Steven, (2012).

$$
n=\frac{N \times p(1-p)}{\left.\left.\llbracket N-1 \times\left(d^{2} \div z^{2}\right)\right]+p(1-p)\right]}
$$

$\mathrm{N}=$ total HCWs population size of $2030+3127$ HCWs including nurses, assistant nurse, and worker from all healthcare facilities at Assiut University Hospitals. By $\mathrm{n}=500$

$\mathrm{Z}=$ confidence levels is 0.95 and is equal to 1.96

$\mathrm{D}=$ the error ratio is $=0.05$

$\mathrm{P}=$ the property availability ratio and neutral $=0.50$

Data collection tools:

Tool I: A 23-item survey instrument developed by WHO, (2020) which applied to all HCWs.

This survey aimed to assess the HCWs' demographic data and the level of their knowledge and perception regarding COVID-19

The questionnaire comprised 3 parts:

Part 1: Demographic characteristics consisted of :

- Age, gender, profession. (3 items),

- Awareness of COVID-19 (2 items)

- Participants' source of information was (4 statements with 4-point, Likert scale: 1 for [least used], 2 for [Sometimes], 3 for [More often] and 4 for [Most used]). In form of "How do rank your sources of information about the Covid-19 outbreak?"

Part 2: Knowledge level: consists (7 questions)

This part contained seven questions about the etiology, incubation period, symptoms, consequences, source of transmission, complications, prevention and treatment of COVID-19.

Each participant was responded as Yes, No and I don't know.

Scoring system: The correct answer was scored as "1" while wrong answer was scored as" $0 "$. A cutoff level of $\leq 4$ was indicated poor knowledge about COVID19 whereas $>4$ was considered adequate knowledge about COVID-19.

Part 3: Perception level: comprised of 7 items: (true or false questions).

These aimed to assess the patrician's perception towards incubation period, the sufficiency of flu vaccine as a prevention, the possibility of the previously infected person's survival, the ideal of preparing food as a protection method, the early detection and early treatment, universal precautions, in addition to cleaning and disinfection methods regarding to COVID-19.

Scoring system: each statement was labeled as good (scored as "1") or poor perception (scored as "0"). Scores ranged from 0 to 7 . The participants' perceptions are classified as good (score $>4$ ) or poor (score $\leq 4$ ).

Tool II: Health care workers' infection control practice observation checklist:

The checklist was developed by the researchers based on time information from CDC and WHO this tool aimed to assess HCWs performance toward general and specific infection control measures regarding COVID 19. It consists of the following 3 main items: 
Part 1: Hand Hygiene Practice

Observations of health care worker's hand hygiene practices were conducted using the WHO patient safety observation form (WHO, 2018), during the "5 moments for hand hygiene", which are;

1) Before touching a patient,

2) Before clean/ aseptic procedures,

3) After body fluid exposure risk,

4) After touching a patient,

(5) After touching patient surroundings.

These observations were performed by the researchers, each observation, during one of the " 5 moments", was recorded as one of three possible actions performed: Hand washing with soap and water, hand rubbing with an alcohol-based solution, or no hand hygiene action done as hand washing is one of the most effective actions that can take to reduce the spread of pathogens and prevent infections, including the COVID-19 virus.

Part 2: Donning and doffing: to assess the steps of wearing and doffing PPE when caring for residents with suspected or confirmed COVID-19, (how to wear and take off gown, N95 respirator, face shield and/or eye goggles, and gloves (CDC, 2020).

Part 3: Coughing etiquette steps: Adopted from; Zayas et al., (2013).

Participants performed a voluntary cough while covering the mouth and nose with the hands, sleeve/arm, tissue, or while wearing a surgical mask. Every participant was encouraged to voluntarily elicit a "real cough" while covering the mouth and nose either with both hands, with a tissue, with the sleeve/arm or while wearing a surgical mask. The researchers observed the participant if perform this correctly or not.

Scoring system: Each item was observed, categorized and scored into either done correctly $=2$, done incorrectly $=1$ or not done $=0$.

The total steps were 55 .

The total score for all items were 110 .

Those who obtained less than $50 \%$ were considered having unsatisfactory level. (50\%) or more were considered having satisfactory level.

Tool III: The Suggested ward based educational package regarding Covid-19:

It was designed by the researcher based on the WHO guidelines, (2018) and the review of relevant literature that relating to the prevention of parenteral infection which have been extensively reviewed by the medical microbiologists, nurses and multidisciplinary team.

The content was selected from the literature and according to the needed of health workers and knowledge and practice that can help to be safe by applying infection control measures regarding COVID-19.
The ward-based educational package sessions consisted of a carefully planned sequence of theoretical and practical demonstration delivered to qualified nurses in the clinical environment at convenient times selected by the ward managers.

Each group received two sessions, one session for theoretical part and the other for practical part, each session took about one hour.

The theoretical part included; definition of COVID 19, modes of transmission, symptoms of novel coronavirus, complications, treatment, and how to reduce the risk of transmission. The practical part of the Suggested Ward-based Educational Package included steps of hand hygiene, steps of putting on and taking off of the PPE.

Each member participating in the study received their own educational package in form of booklet.

Validity and Reliability:

The final form of the tool was designed and tested for reliability by using internal consistency for the tools measured using Cronbach's alpha (tau-equivalent reliability) coefficient for tools ( $\mathrm{r}=0.817$ and 0.75 ).

\section{Administrative design}

An official permission to conduct the proposed study was obtained from the Director of the main Assiut University Hospital. At the initial interview, the researchers introduced themselves to initiate a line of communication and explain the nature and purpose of the study. The data were collected from $1^{\text {st }}$ January 2020 to $30^{\text {th }}$ April 2020.

\section{Ethical consideration}

This study was approved by the ethical committee in the faculty of nursing, Assiut University and guidelines of clinical research according to the principles of Helsinki Declaration, (1996) for medical research, confidentiality and anonymity were guaranteed. Subjects had the freedom to participate and/or withdraw from the study whenever they wanted.

\section{Operational design}

Preparatory phase: It includes reviewing the available literatures concerning the topic of the study. Arabic translation of the study tools was done it took about one month during December 2019. Confidentiality of obtained data was assured by coding the data obtained without names. The aims and the purpose of the study were explained to all participants before starting of data collection.

Pilot study

A pilot study was conducted to test the feasibility, clarity and applicability of the tools on randomly selected (10\%) 50 of HCWs. Feasibility and time required to answer the survey were evaluated on the participants. The needed modifications were done as 
revealed from the pilot study. These participants were not included in the research.

Data were collected from 500 health care workers (nurses, assistant nurse, and workers), inside their work places (word based) in the various hospitals of Assiut University, during fieldwork in the clinical situation through an interviewing questionnaire sheet before applying the suggested ward-based educational package using tools (I \& II).

The total time for collecting the data was about 15 minutes.

This through asking them about all items of the previous mentioned tool (I) and observe them during their routine care of the patients in their ward using tool (II).

Plans were made with the ward managers to perform the suggested ward-based educational package during the convenient times in their wards.

The suggested ward-based educational package (tool III) was administered to the participants in two sessions (all over time was 2hours); the duration of each session was about 1 hours, using roll playing for practice. The study was carried out in the morning shifts. Participants were divided into small groups from 5 to 10 persons to maintain the social distancing for avoiding spread of infection. Around 10 to 12 sessions per month were performed. Through about 50 sessions during the whole study period all participant received the target content of the suggested ward-based educational package (tool III).

First session (theoretical part): The researchers started by introducing themselves to the participants, informing them about the aim of the meeting, and orient them regarding the educational package. Contents of this session include a theoretical part, definition, signs and symptoms, causative organism, and preventive measures of COVID-19 infection control. It took about 1 hour.

Second session (practical part): It started with a summary about what has been discussed in a previous session, objectives of the new session, and contents of this session included a practical part, using the preventive measures for controlling spared of infection represented in the infection control practice as technique and steps of hand washing, wearing and taking off of the PPE, teaching coughing etiquette, using role playing technique and videos. This session ended with a summary of its content and feedback from the participants. Most of the participants were cooperative and interested, as the subject touches the reality and the nature of their work it took about 1 hour.

As the pandemic started to be at the beak of its effect and was difficult to measure the effect of the given educational package on the studied sample knowledge, perception and infection control practice at these emergency circumstances of infection spread and the majority of them worked at the COVID-19 isolation departments. So, it is recommended to reassess their knowledge, perception and practice after the effect of the educational package after diminishing this pandemic.

\section{Statistical design}

The data obtained has been reviewed, prepared for computer entry, coded, analyzed and tabulated. Descriptive statistics (frequencies and percentages, mean and standard deviation.) were done using computer program (SPSS) version (20). Chi-square test was used to assess the relationship between the HCWs' knowledge, perception and practice with their demographic parameters. It's considered significant when $P$. value $\leq 0.05$. 


\section{Results}

Table (1): Demographic characteristics of health care workers( $N=500)$.

\begin{tabular}{|c|c|c|c|}
\hline \multirow{2}{*}{ Demographic characters } & Nurses $(\mathbf{N}=300)$ & assistant nurses $(\mathrm{N}=85)$ & Workers $(\mathrm{N}=115)$ \\
\hline & N. $(\%)$ & N. $(\%)$ & N. $(\%)$ \\
\hline \multicolumn{4}{|l|}{ Gender: } \\
\hline Male & $24(8.0)$ & $2(2.4)$ & 108(93.9) \\
\hline Female & $276(92.0)$ & $83(97.6)$ & $7(6.1)$ \\
\hline \multicolumn{4}{|l|}{ Age } \\
\hline $22-30$ yrs. & $156(52.0)$ & $58(68.2)$ & $16(13.9)$ \\
\hline $31-40$ yrs. & $77(25.7)$ & $27(31.8)$ & $68(59.1)$ \\
\hline$>40$ yrs. & $67(22.3)$ & ------ & $31(27.0)$ \\
\hline Mean \pm SD & $32.003 \pm 8.03$ & $30.2 \pm 4.5$ & $38.6 \pm 7.4$ \\
\hline \multicolumn{4}{|l|}{ Profession } \\
\hline Bachelor & $30(10.0)$ & $\begin{array}{c}--- \\
\end{array}$ & ---- \\
\hline Technical institute & $162(54.0)$ & ----- & $\begin{array}{ll}--- \\
--1\end{array}$ \\
\hline Diplom3yrs & $108(36.0)$ & $34(40.0)$ & $15(13.0)$ \\
\hline Prep school & ---- & $47(55.3)$ & $56(48.7)$ \\
\hline Read and write & $\begin{array}{ll}--- \\
\end{array}$ & $4(4.7)$ & $44(38.3)$ \\
\hline \multicolumn{4}{|l|}{ Heard about COVID-19 } \\
\hline Yes & $300(100.0)$ & $85(100.0)$ & $115(100.0)$ \\
\hline No & $0(0.0)$ & $0(0.0)$ & $0(0.0)$ \\
\hline \multicolumn{4}{|c|}{ Attended lectures or discussions about COVID-19 } \\
\hline Yes & $0(0.0)$ & $0(0.0)$ & $0(0.0)$ \\
\hline No & $300(100.0)$ & $85(100.0)$ & $115(100.0)$ \\
\hline
\end{tabular}

Table (2): Health care workers' source of information about COVID-19. (N=500).

\begin{tabular}{|l|c|c|c|c|}
\hline \multirow{2}{*}{ Source of COVID-19 information } & \multicolumn{3}{|c|}{ HCWs' response } \\
\cline { 2 - 5 } & $\begin{array}{c}\text { Least used } \\
\mathbf{N}(\%)\end{array}$ & $\begin{array}{c}\text { Sometimes } \\
\mathbf{N}(\%)\end{array}$ & $\begin{array}{c}\text { More often } \\
\mathbf{N}(\%)\end{array}$ & $\begin{array}{c}\text { Most used } \\
\mathbf{N}(\%)\end{array}$ \\
\hline -News media & & & & \\
Nurses & $14(4.7)$ & $236(78.7)$ & $10(3.3)$ & $40(13.3)$ \\
assistant nurse & $14(16.5)$ & $23(27.1)$ & $45(52.9)$ & $3(3.5)$ \\
workers & $16(13.9)$ & $21(18.2)$ & $47(40.9)$ & $31(24.0)$ \\
\hline -Social media & & & & \\
Nurses & $0(0.0)$ & $41(13.7)$ & $1(0.3)$ & $258(\mathbf{8 6 . 0})$ \\
assistant nurse & $3(3.5)$ & $0(0.0)$ & $43(50.6)$ & $39(45.9)$ \\
workers & $31(27.0)$ & $0(0.0)$ & $45(39.1)$ & $39(33.9)$ \\
\hline -Government websites & & & & \\
Nurses & $242(80.7), 85(100.0)$, & $10(3.3)$ & $48(16.0)$ & $0(0.0)$ \\
assistant nurse & $115(100.0)$ & $0(0.0)$ & $0(0.0)$ & $0(0.0)$ \\
workers & & $0(0.0)$ & $0(0.0)$ & $0(0.0)$ \\
\hline -Family and friends & & & & \\
Nurses & $15(5.3)$ & $236(78.7)$ & $47(15.7)$ & $1(0.3)$ \\
assistant nurse & $3(3.5)$ & $0(0.0)$ & $43(50.6)$ & $39(45.9)$ \\
workers & $0(0.0)$ & $22(19.1)$ & $62(53.9)$ & $31(27.0)$ \\
\hline
\end{tabular}




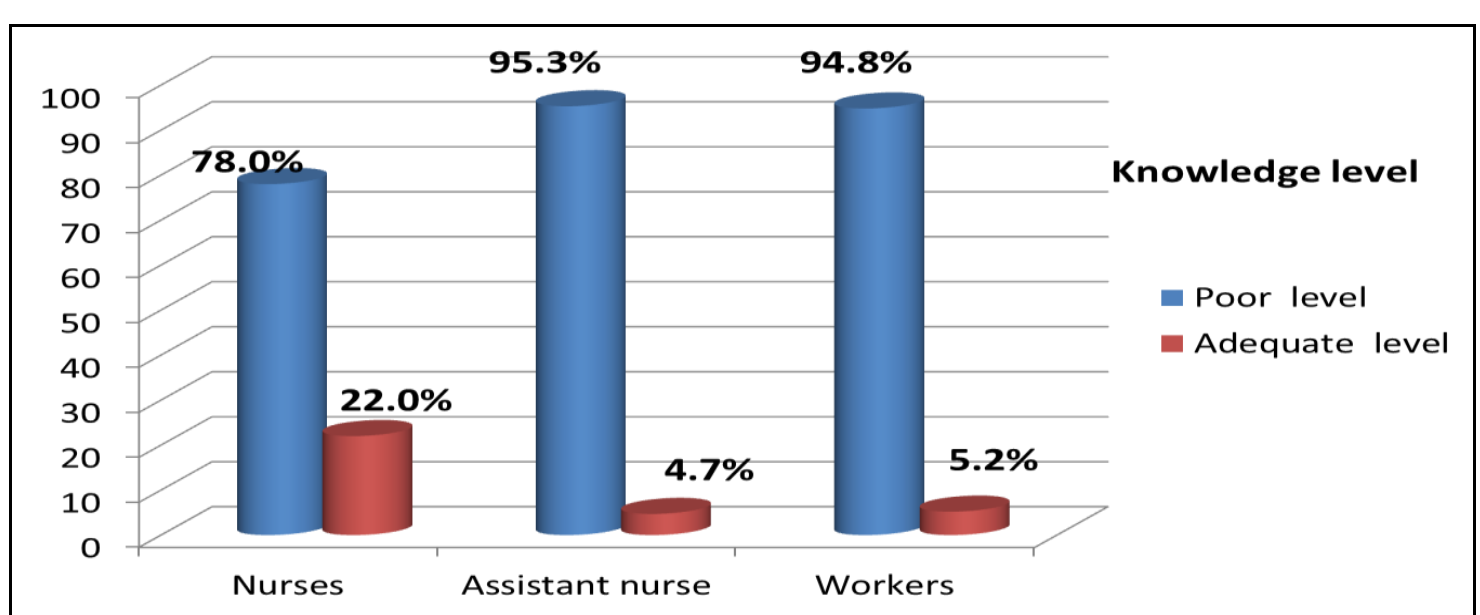

Figure (1): Percentage distribution of studied health care workers' knowledge level toward COVID-19, (N.= 500).

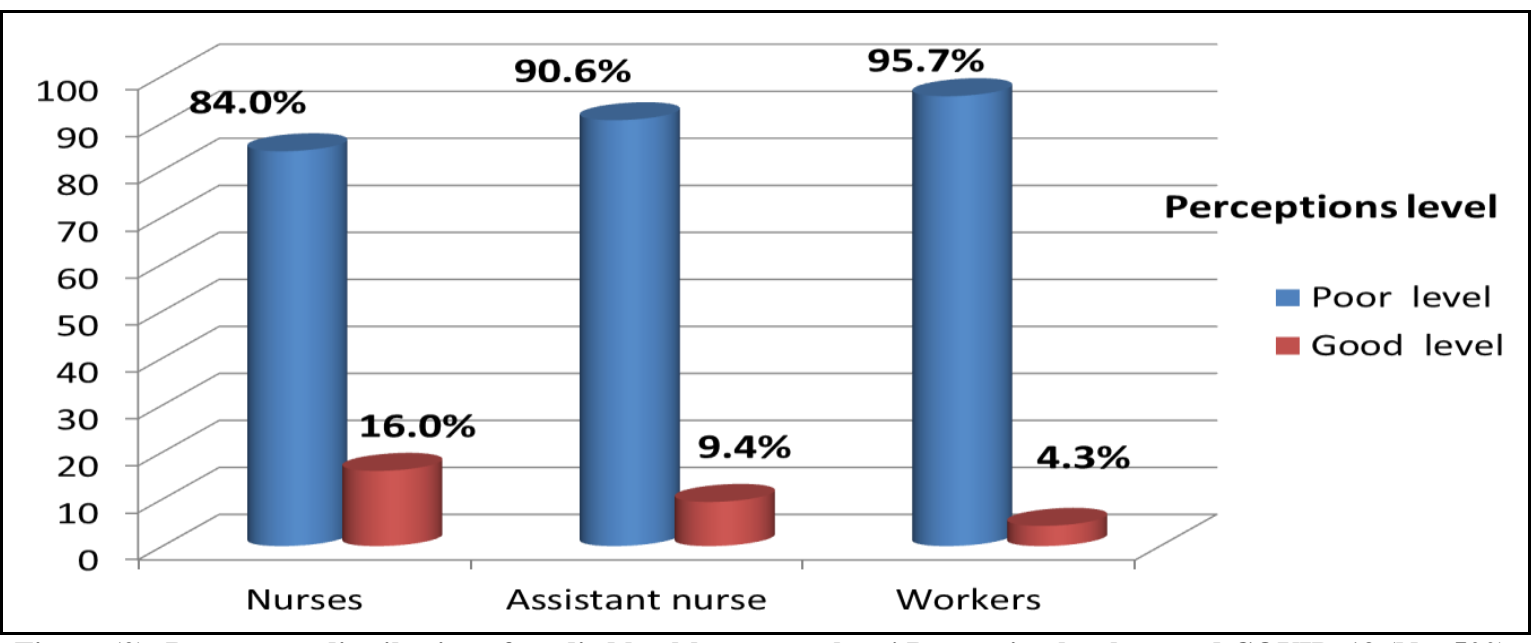

Figure (2): Percentage distribution of studied health care workers' Perception level toward COVID-19 (N. =500).

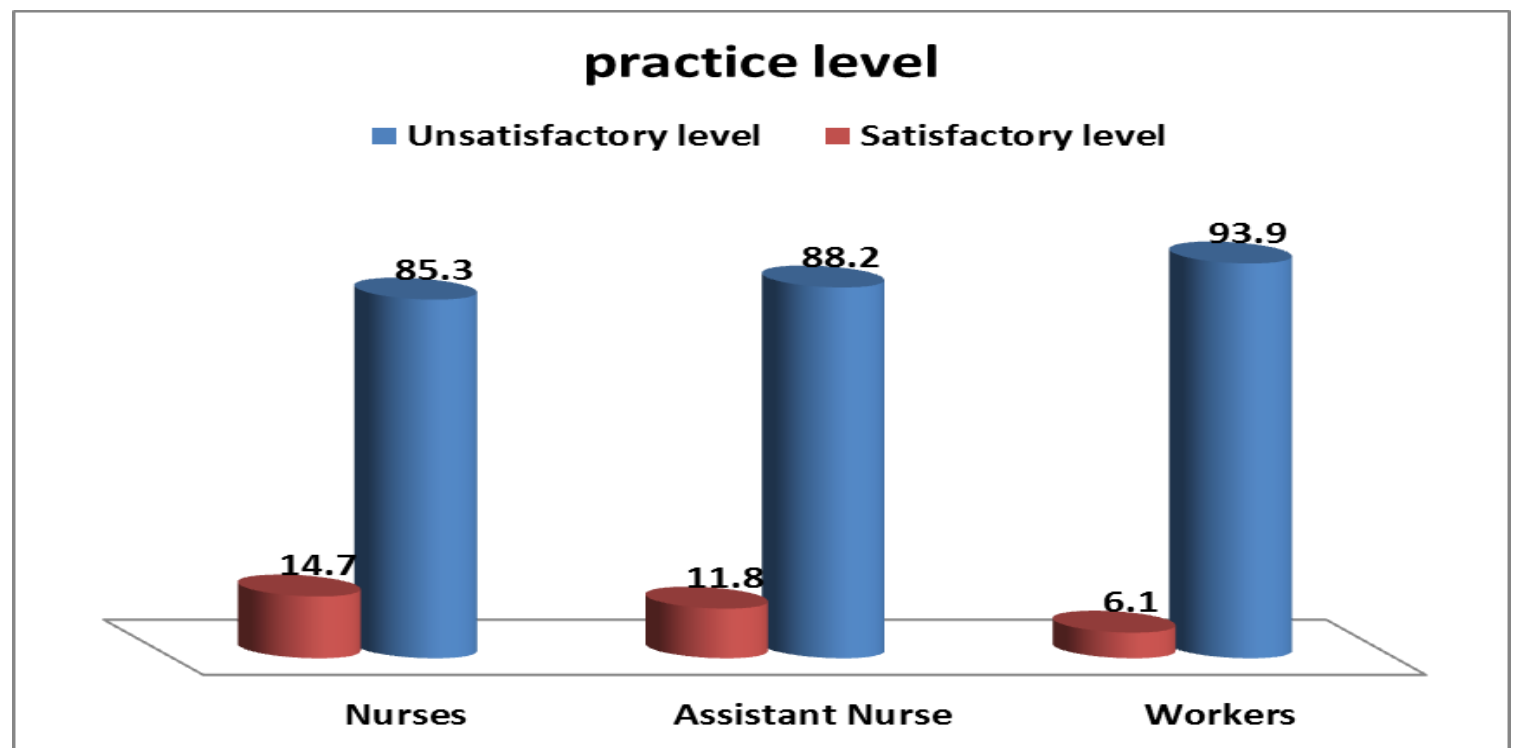

Figure (3): Percentage distribution of studied health care workers' practice level toward COVID-19, (N. =500). 
Table (3): Relation between HCWs' knowledge, practice and perceptions and their demographic characteristics (N. =500).

\begin{tabular}{|c|c|c|c|c|c|c|c|c|c|c|c|c|c|c|c|c|c|c|c|c|c|}
\hline \multirow[b]{3}{*}{ Demographic } & \multicolumn{6}{|c|}{ Knowledge score } & \multicolumn{6}{|c|}{$\begin{array}{l}\text { Practice score } \\
\end{array}$} & \multicolumn{6}{|c|}{ Perception score } & \multirow[b]{3}{*}{$\mathbf{P 1}$} & \multirow[b]{3}{*}{$\mathbf{P 2}$} & \multirow[b]{3}{*}{ P3 } \\
\hline & \multicolumn{3}{|c|}{ Poor } & \multicolumn{3}{|c|}{ Adequate } & \multicolumn{3}{|c|}{ Unsatisfactory } & \multicolumn{3}{|c|}{ Satisfactory } & \multicolumn{3}{|c|}{ Poor } & \multicolumn{3}{|c|}{ Good } & & & \\
\hline & $\begin{array}{l}\text { Nurse } \\
(\mathbf{2 3 4})\end{array}$ & $\begin{array}{r}\text { A.N } \\
(\mathbf{8 1})\end{array}$ & $\begin{array}{c}\text { Work } \\
\text { er } \\
(109)\end{array}$ & $\begin{array}{c}\text { Nurse } \\
(66)\end{array}$ & $\begin{array}{l}\text { A.N } \\
(4)\end{array}$ & $\begin{array}{c}\text { Work } \\
\text { er } \\
(6)\end{array}$ & $\begin{array}{c}\text { Nurse } \\
(256)\end{array}$ & $\begin{array}{l}\text { A.N } \\
(\mathbf{7 5})\end{array}$ & $\begin{array}{c}\text { Work } \\
\text { er } \\
(\mathbf{1 0 8})\end{array}$ & $\begin{array}{c}\text { Nur } \\
\text { se } \\
(44)\end{array}$ & $\begin{array}{l}\text { A.N } \\
(\mathbf{1 0})\end{array}$ & $\begin{array}{c}\text { Work } \\
\text { er } \\
(7)\end{array}$ & $\begin{array}{c}\text { Nurse } \\
(\mathbf{2 5 2})\end{array}$ & $\begin{array}{r}\text { A.N } \\
\text { (77) }\end{array}$ & $\begin{array}{c}\text { Work } \\
\text { er } \\
(110)\end{array}$ & $\begin{array}{c}\text { Nur } \\
\text { se } \\
(48)\end{array}$ & \begin{tabular}{l|}
$\mathbf{A .}$ \\
$\mathbf{N}$ \\
$(\mathbf{8})$
\end{tabular} & $\begin{array}{c}\text { Work } \\
\text { er } \\
(5)\end{array}$ & & & \\
\hline \multicolumn{19}{|l|}{ Age } & \multirow{4}{*}{$\begin{array}{c}0.105 n \\
s\end{array}$} & \multirow{4}{*}{$\begin{array}{c}0.109 n \\
s\end{array}$} & \multirow{4}{*}{$\begin{array}{c}0.083 \\
\mathrm{~ns}\end{array}$} \\
\hline $22-30$ yrs. & 116 & 54 & 13 & 36 & 4 & 3 & 127 & 49 & 44 & 29 & 9 & 0 & 138 & 51 & 15 & 19 & 7 & 1 & & & \\
\hline $31-40$ yrs. & 66 & 27 & 65 & 11 & 0 & 3 & 67 & 26 & 54 & 10 & 1 & 2 & 59 & 26 & 65 & 17 & 1 & 3 & & & \\
\hline$>40$ yrs. & 48 & --- & 31 & 19 & --- & 0 & 62 & - & 10 & 5 & - & 5 & 55 & --- & 30 & 12 & --- & 1 & & & \\
\hline \multicolumn{19}{|l|}{ Gender } & \multirow{3}{*}{$0.003 *$} & \multirow{3}{*}{$\begin{array}{c}0.0001 \\
* * *\end{array}$} & \multirow{3}{*}{$\begin{array}{c}0.019 \\
\text { ns }\end{array}$} \\
\hline Male & 24 & 1 & 103 & 0 & 1 & 5 & 6 & 1 & 102 & 18 & 1 & 6 & 24 & 2 & 103 & 0 & 0 & 5 & & & \\
\hline Female & 210 & 80 & 6 & 66 & 3 & 1 & 250 & 74 & 6 & 26 & 9 & 1 & 228 & 75 & 7 & 48 & 8 & 0 & & & \\
\hline \multicolumn{19}{|l|}{$\begin{array}{c}\text { Level of } \\
\text { education }\end{array}$} & \multirow{6}{*}{$0.005^{*}$} & \multirow{6}{*}{$0.001 *$} & \multirow{6}{*}{$\begin{array}{c}0.011 \\
\mathrm{~ns}\end{array}$} \\
\hline $\begin{array}{l}\text { Bachelorette } \\
\text { degree }\end{array}$ & 30 & --- & --- & 0 & --- & ---- & 19 & - & - & 11 & - & - & 30 & ---- & --- & 0 & ---- & ---- & & & \\
\hline Technical institute & 126 & --- & ---- & 36 & ----- & $\begin{array}{ll}--- \\
\end{array}$ & 139 & - & - & 10 & - & - & 138 & ---- & $\begin{array}{ll}--- \\
\end{array}$ & 24 & ---- & ---- & & & \\
\hline Diplom3yrs & 78 & 33 & 10 & 30 & 1 & 5 & 98 & 32 & 10 & 13 & 2 & 5 & 84 & 33 & 12 & 24 & 1 & 3 & & & \\
\hline Read and write & $\begin{array}{l}--- \\
\end{array}$ & 4 & 44 & --- & 0 & 0 & - & 3 & 44 & - & 1 & 0 & ---- & 3 & 44 & ---- & 1 & 0 & & & \\
\hline Prep school & $\begin{array}{l}---- \\
--\end{array}$ & 44 & 55 & --- & 3 & 1 & - & 40 & 54 & - & 7 & 2 & $\begin{array}{l}--- \\
\end{array}$ & 41 & 54 & ---- & 6 & 2 & & & \\
\hline
\end{tabular}

$\mathrm{P} 1=$ relation between demographic and Knowledge

$P 2=$ relation between demographic and practice

$P 3=$ relation between demographic and Perceptions

Chi-square-test \& One way ANOVA-test 
Table (4): Relationsh between HCWs' knowledge, practice and perceptions and their work categories (N. =500).

\begin{tabular}{|c|c|c|c|c|c|c|c|c|c|}
\hline \multirow{2}{*}{\multicolumn{3}{|c|}{ Health care workers' category }} & \multicolumn{2}{|c|}{ Knowledge score } & \multicolumn{2}{|c|}{ Practice } & \multicolumn{3}{|c|}{ p. value } \\
\hline & & & \multirow{2}{*}{$\begin{array}{c}\text { Poor } \\
210\end{array}$} & \multirow{2}{*}{$\begin{array}{c}\begin{array}{c}\text { Adequat } \\
\text { e }\end{array} \\
42 \\
\end{array}$} & \multirow{2}{*}{$\begin{array}{c}\begin{array}{c}\text { Unsatisfact } \\
\text { ory }\end{array} \\
214 \\
\end{array}$} & \multirow{2}{*}{$\begin{array}{c}\text { Satisfactory } \\
38 \\
\end{array}$} & \multirow{2}{*}{ P. 1} & \multirow{5}{*}{$\begin{array}{c}\text { P.2 } \\
0.362^{\mathrm{ns}}\end{array}$} & \multirow{4}{*}{$\frac{\text { P.3 }}{\underbrace{0.645}_{\mathrm{ns}}}$} \\
\hline Nurses & Perception & Poor & & & & & & & \\
\hline & & Good & 24 & 24 & 42 & 6 & \multirow{3}{*}{$0.001 * *$} & & \\
\hline & Practice & Unsatisfactory & 202 & 54 & - & - & & & \\
\hline & & \begin{tabular}{|l|} 
Satisfactory \\
\end{tabular} & 32 & 12 & - & - & & & \\
\hline Assistance & Perception & Poor & 75 & 2 & 75 & 2 & \multirow{4}{*}{$0.001 * *$} & \multirow{4}{*}{$0.001 * *$} & \multirow{4}{*}{$0.001 * *$} \\
\hline nurse & & Good & 6 & 2 & 0 & 8 & & & \\
\hline & Practice & Unsatisfactory & 75 & 6 & - & - & & & \\
\hline & & \begin{tabular}{|l|} 
Satisfactory \\
\end{tabular} & 6 & 4 & - & - & & & \\
\hline \multirow[t]{4}{*}{ Workers } & \multirow[t]{2}{*}{ Perception } & Poor & 108 & 2 & 108 & 2 & \multirow{4}{*}{$0.001 * *$} & \multirow{4}{*}{$0.001 * *$} & \multirow{4}{*}{$0.001 * *$} \\
\hline & & Good & 1 & 4 & 0 & 5 & & & \\
\hline & \multirow[t]{2}{*}{ Practice } & \begin{tabular}{|l|} 
Unsatisfactory \\
\end{tabular} & 108 & 0 & - & - & & & \\
\hline & & \begin{tabular}{|l} 
Satisfactory \\
\end{tabular} & 1 & 6 & - & - & & & \\
\hline
\end{tabular}

$P 1=$ relation knowledge and perception

$P 2=$ relation knowledge and practice

$P 3=$ relation perception and practice

Chi-square-test \& One way ANOVA-test

Table (1): Shows that regarding to gender, most of the participants from Nurses and assistant nurse were females (92.0\% and $97.0 \%$ respectively), however for workers most of them were males(93,9\%). Most participants were in the mean age $(32.003 \pm 8.03,30.2$ \pm 4.5 , and $38.6 \pm 7.4$ ) respectively. Regarding to profession the majority of nurses having technical institute $(54.0 \%)$, for assistant nurse and workers nearly half (55.3\% and $48.7 \%$ respectively) with preschool. All participants heard about COVID-19 $(\mathrm{n}=500,100.0 \%)$, but none had the opportunity to attend lectures or discussions related to COVID-19.

Table (2): Revealed that majority (86\%) participants' (mainly nurses) as the most used source of obtaining information about COVID-19, were social media (Facebook, Twitter, Whats-App, YouTube, Instagram, Snapchat) and large percentage (40\%) of them used news media (TV/video, magazines, newspapers, and radio)

Figure (1): Concluded that the majority of HCWs (nurses, assistant nurse and workers) had poor level of knowledge about COVID-19, (234 (78.0), 81(95.3), and 109(94.8)) respectively.

Figure (2): Shows that most of HCWs had a poor level of perceptions about COVID-19, (84.0, 90.6 and $95.7 \%$ respectively)

Figure (3): Showed that majority of the HCWs (Nurses, assistant nurse and workers) had unsatisfactory level of practice regarding COIVD-19 (85.3, 88.2 and $93.9 \%$ respectively)

Table (3): Showed that regarding to relation between HCWs' Knowledge and their demographic characteristics, there is no statistical significant statistical difference and their ages, however, there is statistical significant difference regarding their gender and level of education. Regarding to relation between HCWs' practice and their demographic characteristics, there is no statistical significant difference and their ages, however, there is significant statistical difference regarding their gender and level of education. Regarding to relation between HCWs' Perception and their demographic characteristics, there is no statistical significant difference and their ages, gender and level of education.

Table (4): Revealed that regarding to relation between HCWs' Knowledge, practice and perception among health care workers, there is significant statistical difference between HCWs' knowledge and practice, also, HCWs' knowledge and perception except among nurses. Additionally there is significant statistical difference between HCWs' perception and practice except among nurses.

\section{Discussion}

This study was conducted in the middle and early stages of the COVID-19 outbreak in a non-epidemic but still critically affected area. There for this study aimed to assess health care workers' knowledge, perception and infection control regarding Covid-19 and develop the suggested ward-based educational package.

Regarding the demographic data of the studied health care workers at Assiut university hospitals, this study showed that most of the studied nurses and assistant nurse were females, however the studied workers most of them were males. This because the nursing 
schools, high institution and faculty of nursing just accepted only the female as a student. Currently, there is an expansion in the number of men entering the nursing profession.

Undeniable nursing has progressed as a feminine occupation in spite of a few men having performed men jobs since the calling's earliest stages. Likewise, for Egyptian male nurse students, societal image of nursing as profession considered one of the major reasons that put the male students under stress (Onwumere \& Ogbonnaya, 2017).

Regarding profession, more than half of nurses were technical institute graduates while the assistant nurse and workers nearly half of them had a pre-school education. The majority of studied nurses were below 25 years old, this is not in the same line with Mahmoud et al., (2020) who mentioned that; the administrators selected older age nurses to be able to perform mainly tasks in the critical units effectively.

As well, Yousif et al., (2020) reported that the majority of nurses age ranged between 20-40 years, were married, female, and had a diploma of nursing.

Almost all participants in the present study had heard about COVID-19, but no one had the opportunity to attend lectures or discussions related to COVID-19. This might indicate that nurses are not prepared before graduation and the experiences of the nurses have been gained while working only in the actual work field. Therefore, in-service training program is necessary to prepare nurses to handle clinical alarm management at the postgraduate level.

The previous result is in contradiction with Jackson et al., (2019) who stated that health care provision requires in-service training programs for nurses and also stated that continuing professional development through education and training after the point of qualification and or registration help nurses in improvement of patient care and enables professional nurse practitioners to provide quality nursing care and service delivery to their patients.

HCWs' knowledge

The present study revealed that the studied health care workers were more interested in social media to gather information about COVID-19.

This is important for the Egyptian government to consider a variety of channels to update knowledge and learning materials especially, to communicate information to the minority of HCW's who have a lack of knowledge related to COVID-19.

Also, it is necessary that the website of the Ministry of Health or hospitals facilitate its information and easy access in their word bases regularly to encourage HCWs to reach to this channel for all health-related issues and information.

However, this result did not match with previous findings been described by Hoxmeier \& Lenk,
(2020) who found that the highest main source was seminars and workshops for gaining information. However, television was reported by other studies as a main source of knowledge about corona virus (Asaad et al., 2020).

This difference might be explained by the recent advancement in internet technologies and most of the educational materials and health messages on MERSCoV, nowadays, are posted online by the WHO and Egyptian Ministry of Health which may have urged healthcare providers to use internet technology to gain access to those documents. This is supported by other previously conducted research that observed how this way of communicating information has an important impact on healthcare workers' knowledge (Karasneh et al., 2020).

Therefore, it is necessary to reveal this aspect of virus epidemiology to healthcare providers as it is useful in infectious disease surveillance and control may aid in diagnosis if laboratory facilities are unavailable and is clinically relevant in the administration of antiviral medications which are most effective when given before or immediately after (Gane et al., 2020).

This study concluded that the majority of HCWs nurses, assistant nurse and workers had poor level of knowledge about COVID-19. However, inadequate knowledge is not the only risk factor for care. A previous study showed that the causes of higher risk of infection are related to HCWs types and the frequency of their occupational exposure.

The results of the present study are similar to the findings of Zhou et al., (2020) study about MERS. However the present study results are different from a research of Huynh et al., (2020) in which only one third of participants had no knowledge of the treatment of SARS and MERS.

\section{HCW' perception}

Another important finding was that the vast majority of the participants had a poor level of perception toward COVID-19. However, there remains a significant concern that they could contract the virus and in turn pass the virus to family members, particularly their parents.

The participants in the present study responded negatively to the role of health education in disease prevention and this finding was in the same line with another study in which a poor perception of healthcare workers was noted towards active participation in prevention program (Aldohyan et al., 2019).

This matches with Ong et al., (2020) who found that the poorest perception was observed when respondents adversely replied to the questions regarding negative effect of infection, fear from catching infection by a family member, fear to go to 
common, in case of epidemic and risk from handling corona infected patient.

On the other hand, Shiina et al., (2020) found that the good perception was regarding importance of notification, use of face mask during working hours, corona infection is preventable and role of health education in disease prevention.

Some of these responses are in line with different studies related to MERS-CoV infection and other related infections. More than half of healthcare workers in the study of Ahmed et al., (2020) indicated a high level of fear and anxiety from SARS infection, even in the absence of an epidemic, and a high proportion preferred to avoid the patient. Also this result not agreed with the finding reported by Geberemariyam et al., (2018) who found that personal protective equipment should be worn when dealing with healthcare associated infections.

\section{HCWs' infection control practice}

The present study showed that majority of the HCWs (Nurses, assistant nurse and workers) had unsatisfactory level of infection control practice regarding COIVD-19.

Similarly, Ay et al., (2019) reported high level of healthcare workers compliance to infection control practices. Fulford \& Stankiewicz, (2020) reported small number of correct responses to items about hand hygiene and use of surgical mask except the question about waste management. Therefore, a more effective method of measuring compliance would be the direct observation of actual practice (Koyama et al., 2020).

Regarding the relationship between knowledge and demographic characteristics

Regarding HCWs' Knowledge and practice, there is statistical significant difference regarding their gender and level of education. Regarding HCWs' Perception, there is no statistical significant difference and their ages, gender and level of education.

The present study showed that the majority of the studied nurses had a good level of knowledge, practice and perception were from 22 to 30 years old, female and had a technical institute. While the assistance nurses who had a good level of knowledge, practice and perception were from 22 to 30 years old, female and had a preparatory school. Regarding the workers who had a good level of knowledge, practice and perception were from 31 to 40 years old, male and had a diplom3years.

In this study, careful removal of protective equipment was found to be positively associated with a higher education level Therefore, education and training on proper removal of protective equipment should target novices and $\mathrm{HCWs}$ with lower educational attainment. It was also observed that occupation was significantly associated with knowledge and practice. A finding that seems interesting; is the significant association between gender and knowledge \& practice score (no significance with perception scores) with higher mean score among females. This finding disagreed with other studies that found gender to be a significant predictor of knowledge and practice of healthcare workers (Temesgen \& Demissie, 2014).

Similar results were reported by Bahammam, (2018) in study about "Awareness and practice about the association between periodontal diseases and diabetes mellitus. However, there is a need to improve the level of knowledge of all healthcare providers towards the disease. The lack of significant association between perception or practices and age was supported by some reports.

In the same respect nurses showed relatively more knowledge additionally, good knowledge has a higher probability of good perception, this result has not previously been described by (Narayana et al., 2017).

Wingo et al., (2017) concluded that training regarding protection should be organized according to different factors (work experience, educational attainment, and so on), the Research done by Nour et al., (2017) discussed traditional norms and customs in Saudi Arabia that might explain the difference in gender effect on KAP of healthcare workers.

It is possible that male health workers have more interaction and socialization than females, more opportunities to meet other healthcare professionals and specialists, traveling for symposiums, conferences and other health related activities and are more exposed to healthcare system as compared to their female counterpart.

The current study revealed that the there was a statistically significant difference between HCWs' knowledge and practice, also, HCWs' knowledge and perception except among nurses. Additionally, there is statistical significant difference between HCWs' perception and practice except among nurses.

The researchers' opinion that the goals of the upcoming educational program should focus on the HCW's with insufficient knowledge and this should improve the rate of good practice and perception of HCWs. More knowledge among nurses, compared to other healthcare providers, might be explained by their greater opportunities of professional development, clinical training and previous experience with similar viral infections of epidemic potential. Similar positive correlation between knowledge and practice of healthcare workers was reported by Gupta et al., (2015) among HCWs. 
In view of this, it could be established that adequate knowledge can lead to good practice that could be explained by Neutzling et al., (2019) who explained that a person's intention to a specific behavior is predicted by his perception toward that behavior and how he thinks other people would view him if he performed the behavior.

Thus it could be concluded that correct knowledge results in good perception which could be translated into practice to achieve desirable outcomes (Hardy et al., 2019).

In summary, we are able to identify specific knowledge and perception gaps to be addressed and the major issues that need emphasis during implementation of future intervention programs to raise awareness and improve capacities of healthcare providers in Assiut University hospitals towards Covid-19 infection. However, it is important to interpret the results in the context of potential study limitations.

\section{Conclusion}

Protecting healthcare workers is a public health priority to meet this global threat of COVID-19. So, it was necessary to assess the HCWs knowledge and infection control practices regarding the pandemic and improve it.

\section{Recommendations}

- Urgently implement strategies as educational interventions to protect healthcare workers in the time of the COVID-19 pandemic.

- Conduct the suggested Ward-based Educational package for all Health Care Workers who working in Assiut University Hospitals.

- Further studies are needed about highly transmittable pathogen to keep up with what the world is currently facing from the COVID19 pandemic.

Declaration of conflicting interests

The authors declare that there is no conflict of interest Funding

The authors declare that they have not received any direct or indirect funding from any organization for the research.

\section{Acknowledgments}

We would like to thank all the health care workers at Assiut University Hospitals for their efforts to combat this pandemic.

\section{References}

1. Ahmed, M., Jouhar, R., Ahmed, N., Adnan, S., Aftab, M., Zafar, M., \&Khurshid, Z., (2020): Fear and practice modifications among dentists to combat Novel Coronavirus Disease (COVID-19) outbreak. International journal of environmental research and public health, 17(8), 2821.

2. Aldohyan, M., Al-Rawashdeh, N., Sakr, F., Rahman, S., Alfarhan, A., \& Salam, M., (2019): The perceived effectiveness of MERS$\mathrm{CoV}$ educational programs and knowledge transfer among primary healthcare workers: a cross-sectional survey. BMC infectious diseases, 19(1), 273.

3. Alshahrani, H., (2020): Evaluating the Impact of Continuing Professional Development within Intensive Care Unit Nurses in the UK. American Journal of Nursing Research, 8(2), 227-244.

4. Asaad, A., El-Sokkary, R., Alzamanan, M., \& El-Shafei, M., (2020): Knowledge and attitudes towards Middle East respiratory syndrome-coronavirus (MERS-CoV) among health care workers in south-western Saudi Arabia. East Mediterr Health J, 25 (1), 30.

5. Assiut University Hospital records, (2020).

6. Ay, P., Teker, A., Hidiroglu, S., Tepe, P., Surmen, A., Sili, U., \& Karavus, M., (2019): A qualitative study of hand hygiene compliance among health care workers in intensive care units. The Journal of Infection in Developing Countries, 13(02), 111-117.

7. Bahammam, M., (2018): Awareness and practice about the association between periodontal diseases and diabetes mellitus: a cross-sectional study in Western Saudi Arabia among health care providers. Journal of Multidisciplinary Healthcare, 11(2), 511.

8. Bhagavathula, A., Aldhaleei, W., Rahmani, J., Mahabadi, M., \& Bandari, D., (2020): Novel coronavirus (COVID-19) knowledge and perceptions: a survey on healthcare workers, 678.

9. CDC, Center of Disease Control and prevention (2020): Using Personal Protective Equipment (PPE), available at: https://www.cdc.gov/coronavirus/2019ncov/hcp/using-ppe.html

10. Elmeiligy, M., Desouky, A., \& Elghamrawy, S., (2020): A Multi-Dimensional Big Data Storing System for Generated COVID-19 Large-Scale Data using Apache Spark, 451.

11. Fulford, M., \&Stankiewicz, N., (2020): Hand Hygiene and Personal Protection. In Infection Control in Primary Dental Care, Springer, Cham, 29-41.

12. Gane, E., Charlton, M., Mohamed, R., Sollano, J., Tun, K., Pham, T., \& Zhuang, H., (2020): Asian consensus recommendations 
on optimizing the diagnosis and initiation of treatment of hepatitis B virus infection in resource-limited settings. Journal of Viral Hepatitis, 27(5), 466-475.

13. Geberemariyam, B., Donka, G., \& Wordofa, B., (2018): Assessment of knowledge and practices of healthcare workers towards infection prevention and associated factors in healthcare facilities of West Arsi District, Southeast Ethiopia: a facility-based cross-sectional study. Archives of Public Health, 76(1), 69.

14. Gupta, S., Nayak, R., Shivaranjani, R., \& Vidyarthi, S., (2015): A questionnaire study on the knowledge, attitude, and the practice of pharmacovigilance among the healthcare professionals in a teaching hospital in South India. Perspectives in clinical research, 6(1), 45.

15. Hardy I., Day, E., \& Arthur Jr, W., (2019): Exploration-exploitation tradeoffs and information-knowledge gaps in self-regulated learning: Implications for learner-controlled training and development. Human Resource Management Review, 29(2), 196-217.

16. Helsinki F., (1996): World medical association declaration of Helsinki, Recommendations guiding physicians in biomedical research involving human subjects, Adopted by the 18thWorld Medical Assembly, p 17c.

17. Hoxmeier, J., \& Lenk, M., (2020): Servicelearning in information systems courses: Community projects that make a difference. Journal of Information Systems Education, 14(1), 10

18. Huang, S., Zhang, Z., Wu, Y., Mei, S., Li, Y., Xie, X., \& Wu, Y., (2020): Evolving Epidemiology and Effect of Nonpharmaceutical Interventions on the Epidemic of Coronavirus Disease in Shenzhen, China. medRxiv., 20(8),451.

19. Huynh, G., Nguyen, T., Vo, K., \& Pham, L., (2020): Knowledge and attitude toward COVID-19 among healthcare workers at District 2 Hospital, Ho Chi Minh City. Asian Pacific Journal of Tropical Medicine, 13(6), 260.

20. Jackson, L., Jowsey, T., \& Honey, M., (2019): In-Service Education: Evolving Internationally to Meet Nurses' Lifelong Learning Needs. The Journal of Continuing Education in Nursing, 50(7), 313-318

21. Karasneh, R., Al-Azzam, S., Muflih, S., Soudah, O., Hawamdeh, S., \& Khader, Y., (2020): Media's effect on shaping knowledge, awareness risk perceptions and communication practices of pandemic COVID-19 among pharmacists. Research in Social and Administrative Pharmacy, 77(8),130-140.

22. Koyama, A., Maddox, C., Li, L., Bucknall, T., \& Westbrook, J., (2020): Effectiveness of double checking to reduce medication administration errors: a systematic review. BMJ Quality \& Safety, 29(7), 595603.

23. Mahmoud, E., EL-shafie, O., \& Abdel-Aziz, M., (2020): Effect of Educational Program forNurses Performance Regarding Infection Control Precautions, toward patient on Mechanical Ventilation. Assiut Scientific Nursing Journal, 8(20), 94-104

24. Narayana, G., Suchitra, M., Sunanda, G., Ramaiah, J., Kumar, B., \& Veerabhadrappa, K., (2017): Knowledge, attitude, and practice toward cervical cancer among women attending Obstetrics and Gynecology Department: A cross-sectional, hospital-based survey in South India. Indian journal of cancer, 54(2), 481.

25. Neutzling, M., Pratt, E., \& Parker, M. (2019): Perceptions of learning to teach in a constructivist environment. Physical Educator, 76(3), 756-776.

26. Nour, M., Babalghith, A., Natto, H., Alawneh, S., \& Elamin, F., (2017): Raising awareness of health care providers about MERSCoV infection in public hospitals in Mecca, Saudi Arabia. East Mediterr Health J, 23(8), 534-42.

27. Ong, C., Migliori, G., Raviglione, M., MacGregor-Skinner, G., Sotgiu, G., Alffenaar, J., \& Brusin, S., (2020): Epidemic and pandemic viral infections: impact on tuberculosis and the lung. A consensus by the World Association for Infectious Diseases and Immunological Disorders (WAidid), Global Tuberculosis Network (GTN) and members\# of ESCMID Study Group for Mycobacterial Infections (ESGMYC). European Respiratory Journal, 6(8), 88-97.

28. Onwumere, I., \& Ogbonnaya, N., (2017): Determination of Factors Influencing Male Students from Choosing Nursing as a Career in Enugu Urban Nigeria. NG-Journal of Social Development, 417(5469), 1-11

29. Shiina, A., Niitsu, T., Kobori, O., Idemoto, K., Hashimoto, T., Sasaki, T., \& Iyo, M., (2020): Relationship between perception and anxiety about COVID-19 infection and risk behaviors for spreading infection: A national 
survey in Japan. Brain, Behavior, \& Immunity-Health, 4(7), 67-80.

30. Steven K., Thompson (2012): sample size, 960.

31. Temesgen, C., \& Demissie, M., (2014): Knowledge and practice of tuberculosis infection control among health professionals in Northwest Ethiopia; 2011. BMC health services research, 14(1), 593.

32. Wingo, N. P., Ivankova, N. V., \& Moss, J. A. (2017): Faculty perceptions about teaching online: Exploring the literature using the technology acceptance model as an organizing framework. Online Learning, 21(1), 15-35.

33. World Health Organization (2018): Guidelines on Hand Hygiene in Health Care: First Global Patient Safety Challenge Clean Care is Safer Care, available at: http://whqlibdoc.who.int/publications/eng; 2009

34. World Health Organization, (2020): Emerging respiratory viruses, including COVID-19: methods for detection, prevention, response, and control URL: https://openwho.org/courses/introduction-toncov.

35. Yousif, N., El Shinawy, O., Daef, E., \& ElShafiey, O., (2020): Designed Education Program for Nurses about Immediate and Long Term Nursing Management of Patient with Status Asthmaticus in El-Mobara Hospital at Assiut Governorate. Assiut Scientific Nursing Journal, 8(20), 141-154

36. Zayas, G., Chiang, M., Wong, E., MacDonald, F., Lange, C., Senthilselvan, A., \& King, M., (2013). Effectiveness of cough etiquette maneuvers in disrupting the chain of transmission of infectious respiratory diseases. BMC Public Health, 13(1), 811.

37.Zhang, J., Keegan, B., Lv, Q., \& Tan, C., (2020): A Tale of Two Communities: Characterizing Reddit Response to COVID19, 390-400.

38. Zhou, M., Tang, F., Wang, Y., Nie, H., Zhang, L., You, G., \& Zhang, M., (2020): Knowledge, attitude and practice regarding COVID-19 among health care workers in Henan, China. Journal of Hospital Infection, 87-90. 